Article

\title{
Effects of Sorafenib on $C$-Terminally Truncated Androgen Receptor Variants in Human Prostate Cancer Cells
}

Friedemann Zengerling ${ }^{1,2, \dagger, *}$, Wolfgang Streicher ${ }^{3, \dagger}$, Andres J. Schrader ${ }^{1}$, Mark Schrader ${ }^{1}$, Bianca Nitzsche ${ }^{2}$, Marcus V. Cronauer ${ }^{1}$ and Michael Höpfner ${ }^{2}$

1 Department of Urology, Ulm University, Ulm 89075, Germany; E-Mails: ajschrader@gmx.de (A.J.S.); mark.schrader@uniklinik-ulm.de (M.S.); marcus.cronauer@uni-ulm.de (M.V.C.)

2 Department of Physiology, Charité Universitätsmedizin, Campus Benjamin Franklin, Berlin 14195, Germany; E-Mails: bianca.nitzsche@charite.de (B.N.); michael.hoepfner@charite.de (M.H.)

3 Institute of General Zoology and Endocrinology, Ulm University, Ulm 89069, Germany; E-Mail: wolfgang.streicher@uni-ulm.de

$\dagger$ These authors contributed equally to this work.

* Author to whom correspondence should be addressed;

E-Mail: friedemann.zengerling@uniklinik-ulm.de; Tel.: +49-731-500-58036;

Fax: +49-731-500-58002.

Received: 7 August 2012; in revised form: 5 September 2012 / Accepted: 6 September 2012 / Published: 14 September 2012

Abstract: Recent evidence suggests that the development of castration resistant prostate cancer (CRPCa) is commonly associated with an aberrant, ligand-independent activation of the androgen receptor (AR). A putative mechanism allowing prostate cancer (PCa) cells to grow under low levels of androgens, is the expression of constitutively active, $C$-terminally truncated AR lacking the AR-ligand binding domain (LBD). Due to the absence of a LBD, these receptors, termed $\mathrm{AR} \triangle \mathrm{LBD}$, are unable to respond to any form of anti-hormonal therapies. In this study we demonstrate that the multikinase inhibitor sorafenib inhibits AR as well as AR $\triangle$ LBD-signalling in CRPCa cells. This inhibition was paralleled by proteasomal degradation of the AR- and AR $\triangle \mathrm{LBD}$-molecules. In line with these observations, maximal antiproliferative effects of sorafenib were achieved in AR and AR $\triangle \mathrm{LBD}$-positive PCa cells. The present findings warrant further investigations on sorafenib as an option for the treatment of advanced AR-positive PCa. 
Keywords: sorafenib; truncated androgen receptor variants; castration resistant prostate cancer

\section{Introduction}

Prostate cancer ( $\mathrm{PCa}$ ) is the most common neoplasm and the third leading cause of cancer-related deaths in elderly men of the western world [1]. Localized PCa is treatable and potentially curable by radical prostatectomy or radiation therapy. As most $\mathrm{PCa}$ cells depend on androgens for growth and survival, current treatment for non-organ confined $\mathrm{PCa}$ is mainly based on androgen deprivation (AD) like surgical or chemical castration and/or systemic administration of anti-androgens. Although the majority of $\mathrm{PCa}$ initially responds well to $\mathrm{AD}$, complete remissions are rare and most tumors recur in a more aggressive form that does no longer respond to endocrine therapies. For this stage of the disease, also designated as castration resistant PCa (CRPCa), treatment options are limited and palliative.

Continued androgen receptor (AR)-signalling remains the dominant growth pathway in prostate cancer progressing under low levels of circulating androgens [2]. Various mechanisms have been described to explain the aberrant activation of AR-mediated signalling in CRPCa cells: These include AR-gene amplification and/or overexpression of AR-protein (hypersensitive pathway), point mutations that broaden ligand-specificity of the AR (promiscuous pathway), AR-activation by peptide growth factors or cytokines (outlaw pathway) as well as intratumoral steroid synthesis (backdoor pathway) $[3,4]$. Synthesis of $C$-terminally truncated AR-variants has emerged as an important mechanism of CRPCa cells to grow and survive under subphysiological levels of circulating androgens [5-7]. As the ligand binding domain (LBD) of the $\mathrm{AR}$ is localized in the $C$-terminus, these AR-variants are referred to as AR $\triangle$ LBD. Several molecular mechanisms enabling CRPCa cells to synthesize AR $\triangle$ LBD have been identified: Most AR $\triangle$ LBD found in cell lines and tissue specimens of metastatic PCa are products of alternative splicing (AR-V) $[5,8,9]$. However, nonsense mutations in the LBD or hinge region of the $\mathrm{AR}\left(\mathrm{AR}^{\mathrm{Q} 640 \mathrm{X}}\right)[6]$ as well as enzymatic cleavage of the AR protein [7,10] have also been described to generate $\mathrm{AR} \triangle \mathrm{LBD}$. In contrast to full length $\mathrm{AR}$, which translocates into the nucleus upon androgenic stimuli, many AR $\triangle \mathrm{LBD}$ are able to enter the nucleus even in the absence of androgens $[5,6]$. Although AR $\triangle$ LBD largely vary in their synthesis, a recently described core domain consisting of the AR $N$-terminal domain and the DNA-binding domain (NTD/DBD core) is sufficient for AR-variants to access the nucleus and to activate AR-target genes [11]. Due to the absence of a functional LBD, the constitutively active AR $\triangle \mathrm{LBD}$ are insensitive towards classical endocrine therapies, which either directly target the LBD (antiandrogene therapies) or indirectly target LBD-function by suppression of androgen synthesis. Moreover, aberrant reactivation of AR-signalling by AR $\triangle$ LBD has recently been suggested to contribute to resistance to anti-hormonal treatments with CYP17 inhibitors, such as abiraterone [12]. Thus, there is an urgent need for new therapies targeting ligand-independent AR-signalling in CRPCa cells to expand the therapeutic options for the treatment of advanced PCa.

AR-function as well as AR-stability largely depend on post-translational modifications like phosphorylation on serine/threonine or tyrosine residues $[13,14]$. Recently, Oh et al. reported that the multikinase inhibitor sorafenib (Nexavar, BAY 43-9006) was able to decrease proliferation of PCa 
cells via inhibition of the canonical AR-signalling pathway. Inhibition of AR-signalling was paralleled by a downregulation of AR protein-levels [15]. As most AR phosphorylation sites are located at the $N$-terminus [13], a region shared by both, full length $\mathrm{AR}$ and AR $\triangle \mathrm{LBD}$, we hypothesized that sorafenib might also affect AR $\triangle \mathrm{LBD}$-function. Therefore, we investigated the effect of sorafenib on ARALBD-signalling using AR-negative PC-3 cells transiently transfected with the AR $\triangle$ LBD-variant $\mathrm{AR}^{\mathrm{Q} 640 \mathrm{X}}$ as well as the AR/AR-V expressing PCa cell line 22Rv1 as experimental models.

\section{Results and Discussion}

\subsection{Sorafenib Inhibits Canonical AR-Signalling in PCa Cells}

Recently, sorafenib was shown to target AR-signalling in $\mathrm{LNCaP}$ and castration resistant LNCaP-sublines (LNCaP-abl, LNCaP-IL6+, LNCaP-Bic) [15]. As LNCaP cells express a promiscuous full length AR (919 amino acids, point mutation in the LBD, T877A) [16], we analyzed the effects of sorafenib on AR-signalling in PC-3 cells transiently transfected with a wild type AR. As seen in Figure 1, sorafenib diminished transactivation of AR-dependent reportergene constructs (ARE(2x), PSA) in PC-3 cells. Inhibition was already significant for the PSA-reporter at a concentration of $2.5 \mu \mathrm{M}$ (downregulation versus DHT-treated controls: $23 \% \pm 11 \%, p=0.034$ ), reaching its maximum at $10 \mu \mathrm{M}$, (downregulation versus DHT-treated controls: $60 \% \pm 10 \%, p<0.001$; Figure 1A). Inhibition of $\operatorname{ARE}(2 \mathrm{x})$-promoter construct was relatively weak but statistically significant at concentrations $>5 \mu \mathrm{M}$ (downregulation versus DHT-treated controls at $7.5 \mu \mathrm{M}, 22 \% \pm 6 \%, p=0.033$ ) reaching its maximum at $10 \mu \mathrm{M}$ (downregulation 32\% $\pm 4 \%, p=0.002$; Figure 1B). The reportergene assays are in agreement with previous findings, showing a sorafenib-induced downregulation of prostate specific antigen (PSA) in LNCaP and castration resistant LNCaP sublines [15].

Figure 1. Sorafenib inhibits androgen receptor (AR)-signalling in prostate cancer ( $\mathrm{PCa})$ cells. PC-3 cells were cotransfected with an AR-expression construct together with an AR-dependent (A) Prostate specific antigen (PSA) or (B) ARE(2x)-reporter plasmid. pRL-tk-LUC was co-transfected as an internal control for transfection efficiency. Reportergene activity after sorafenib treatment (SORA) was measured using a Dual-Luciferase Reporter Assay as recently described [17]. Results are expressed in percent transactivation of dihydrotestosterone (DHT)-treated cells which were set at 100\%; $* p<0.05 ; * * p<0.01 ; * * * p<0.001$.
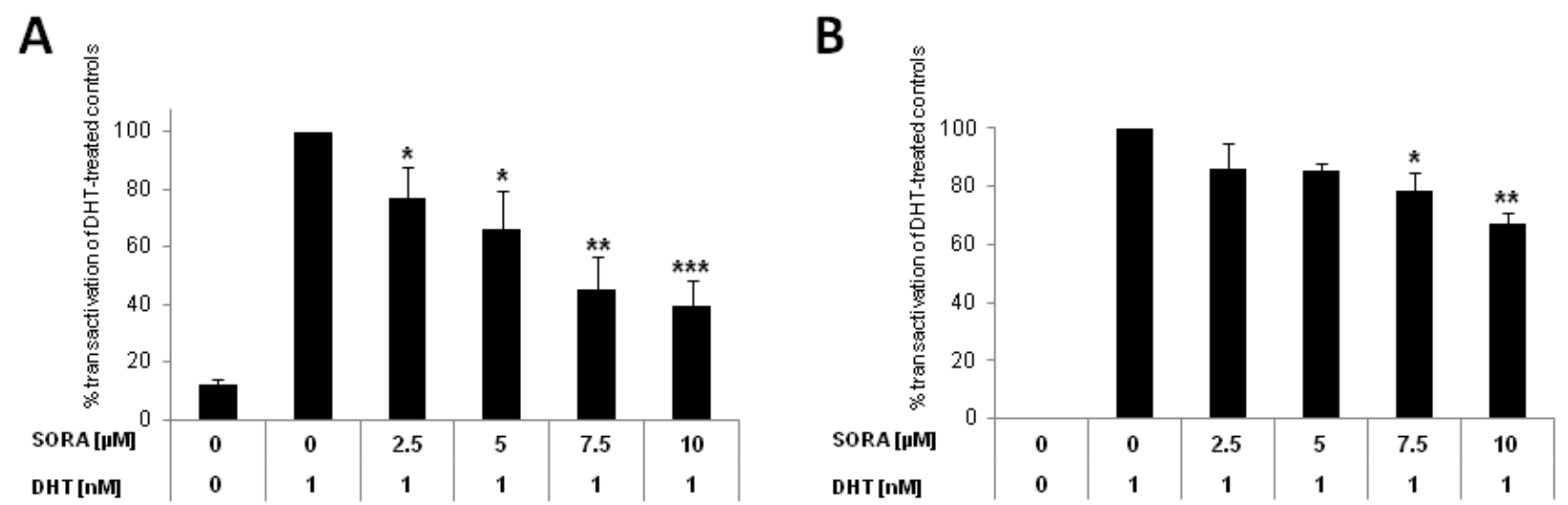


\subsection{Effect of Sorafenib on Constitutively Active, C-Terminally Truncated AR-Mutant Q640X}

Posttranslational modifications like phosphorylation on serine, threonine or tyrosine residues are involved in a large variety of steroid receptor functions $[13,14]$. Based on recent findings by Oh et al. it is tempting to speculate that the multikinase-inhibitor sorafenib targets the AR phosphorylation via blockade of a yet undefined kinase [15]. As the majority of AR phosphorylation sites are located at the $\mathrm{N}$-terminus of the receptor molecule, we hypothesized that sorafenib might also affect phosphorylation of the AR $\Delta$ LBD- $N$-terminus.

As an experimental model we transfected PC-3 cells with the AR-mutant $\mathrm{AR}^{\mathrm{Q} 640 \mathrm{X}}$, the product of a nonsense mutation leading to a stop codon in the hinge region adjacent to the LBD of the AR [6]. Transactivational activity of $\mathrm{AR}^{\mathrm{Q} 640 \mathrm{X}}$ was shown to be very strong on artificial androgen-responsive promoters $(\operatorname{ARE}(2 x))$ but was very weak on the PSA promoter $[17,18]$. In contrast to the wild type AR many $\mathrm{AR} \triangle \mathrm{LBD}$ are unable to activate the full panel of androgen-dependent genes [17-19]. As seen in Figure 2 sorafenib was able to inhibit transactivation of the constitutively active, $C$-terminally truncated $\mathrm{AR}^{\mathrm{Q} 640 \mathrm{X}}$ in a dose-dependent manner. Inhibition was significant at a concentration of $5 \mu \mathrm{M}$ (downregulation versus untreated controls: $30 \% \pm 7 \%, p=0.012$ ), reaching its maximum at $10 \mu \mathrm{M}$ (downregulation versus untreated controls: $46 \% \pm 8 \%, p=0.003$ ). The data suggest that sorafenib affects wild type AR and AR $\triangle \mathrm{LBD}$ signalling in a similar way.

Figure 2. Sorafenib inhibits $\mathrm{AR}^{\mathrm{Q} 640 \mathrm{X}}$-signalling in $\mathrm{PC}-3$ cells. $\mathrm{AR}$ negative $\mathrm{PC}-3$ cells were cotransfected with an $\mathrm{AR}^{\mathrm{Q} 640 \mathrm{X}}$ construct ( $\mathrm{AR}$ with point mutation in the hinge region, 640 amino acids) together with an $\mathrm{ARE}(2 \mathrm{x})$-reporter plasmid. pRL-tk-LUC was co-transfected as an internal control for transfection efficiency. Reportergene activity after sorafenib treatment (SORA) was measured using a Dual-Luciferase Reporter Assay as recently described [17]. Results are expressed in percent transactivation of untreated controls which were set at $100 \% ; * p<0.05 ; * * p<0.01$.

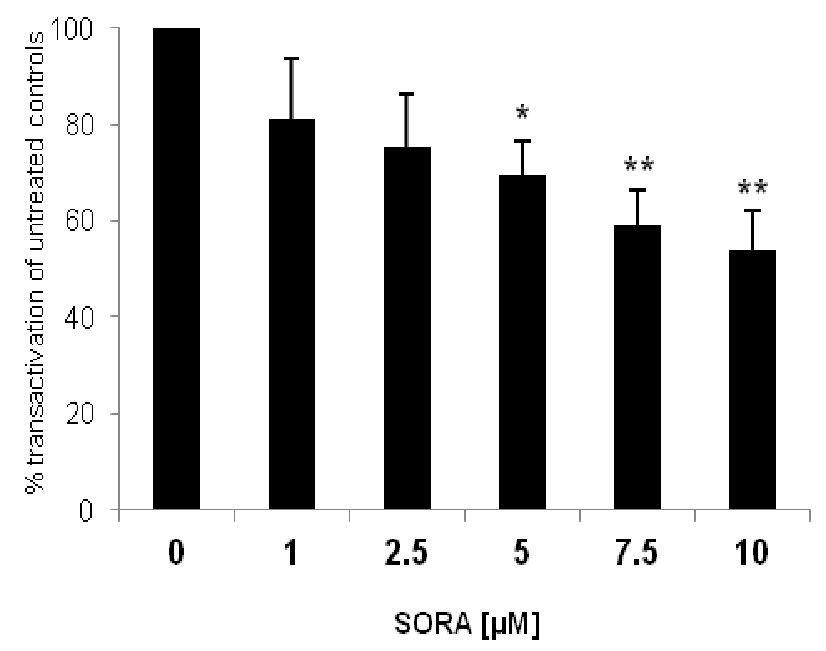

\subsection{Sorafenib Induces Proteasomal Degradation of AR and AR-V Splice Variants in 22Rv1 Cells}

There is experimental evidence that kinase inhibitors directed against p42/p44 MAPK, GSK-3 $\beta$ or CDK1 are able to trigger AR-signalling by modulating AR-protein levels [20-22]. Recently, the 
multikinase inhibitor sorafenib was shown to diminish PSA-levels in LNCaP and its bicalutamide resistant subline LNCaP-Bic. The reduction in PSA-levels was paralleled by a decrease of full length AR [15]. The observation that sorafenib is able to downregulate intracellular AR-levels prompted us to analyze its effects on intracellular AR $\triangle \mathrm{LBD}$ levels. Although transient expression of $\mathrm{AR}^{\mathrm{Q} 640 \mathrm{X}}$ is largely sufficient to perform reportergene assays (Figure 2), the expression levels of the $\mathrm{AR}^{\mathrm{Q} 640 \mathrm{X}}$ protein transfected into PC-3 cells are too low to perform a western blot analysis. Therefore we tested the effects of sorafenib on ARALBD-levels in 22Rv1 cells, known to express large amounts of the AR-splicing variant AR-V7 [23]. Although $\mathrm{AR}^{\mathrm{Q} 640 \mathrm{X}}$ and $\mathrm{AR}-\mathrm{V7}$ are generated by different mechanisms, both AR $\triangle \mathrm{LBD}$ receptor forms share several common features like identical transactivation and DNA-binding domains, receptor size (AR-V7: 642 amino acids; $\mathrm{AR}^{\mathrm{Q} 640 \mathrm{X}}$ : 640 amino acids), predominant nuclear localization in the absence of androgens and constitutive activity as shown by activation of PSAP1 luciferase reporter plasmid [23].

Interestingly, sorafenib was able to diminish both full length AR as well as AR-V in 22Rv1 cells. Downregulation of AR and AR-V protein levels following sorafenib treatment could be rescued by the proteasome inhibitor MG132, the latter suggesting that sorafenib induces a proteasomal degradation of AR- and AR $\triangle \mathrm{LBD}$ molecules in PCa cells (Figure 3).

Figure 3. Downmodulation of $A R$ and $A R-V$ in $22 R v 1$ cells is due to sorafenib induced proteasomal degradation. 22Rv1 cells were incubated with the proteasome inhibitor MG132 $(5 \mu \mathrm{M})$ for $60 \mathrm{~min}$ followed by treatment with sorafenib $(5 \mu \mathrm{M})$ for $18 \mathrm{~h}$. Subsequently cell extracts were analyzed by Western blot analysis (AR: androgen receptor; AR-V, AR $\triangle$ LBD generated by alternative splicing; $\beta$-actin: loading control; ctrl: untreated control; SORA: sorafenib; MG132: proteasome inhibitor). AR, AR-V and $\beta$-actin levels were quantified by densitometry and expressed as fold-change of $A R / \beta$-actin or AR-V/ $\beta$-actin control (ctrl) levels which were set at 1.00 .

MG132

Ctrl SORA SORA MG132
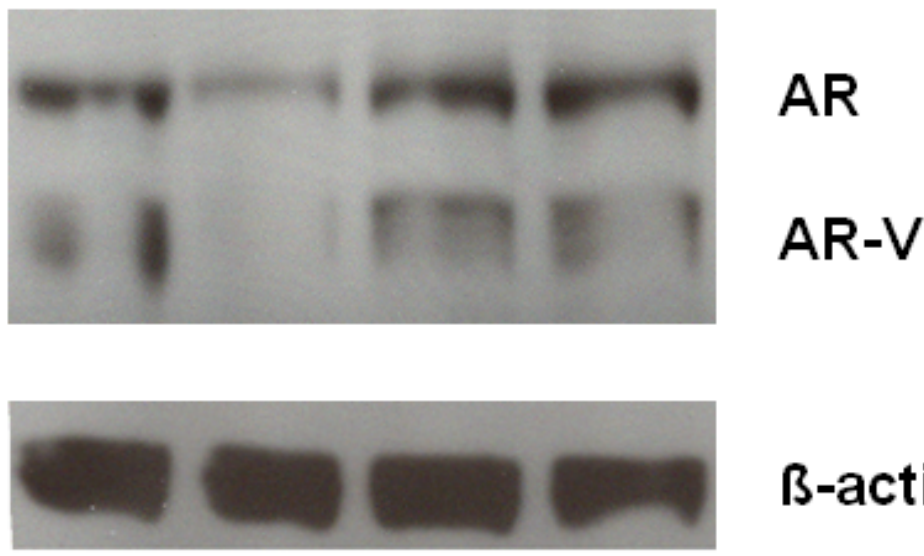

\section{ß-actin}

$\begin{array}{lllll}1.00 & 0.35 & 1.10 & 1.58 & \text { AR } / \text { B-actin } \\ 1.00 & 0.15 & 0.92 & 1.08 & \text { AR-V } / \text { B-actin }\end{array}$




\subsection{Sorafenib Does not Modulate the Subcellular Distribution of AR and AR LLBD in PCa Cells}

Besides its effects on AR-stability, various kinase inhibitors were shown to modulate the intracellular localization of the AR [21,24-26]. In consequence we wondered whether the multikinase inhibitor sorafenib is also able to modulate subcellular distribution of AR-molecules. Therefore, we transfected PC-3 cells with expression plasmids coding for green fluorescent $\mathrm{AR}$ - and $\mathrm{AR}^{\mathrm{Q} 640 \mathrm{X}}$-fusion proteins. As seen in Figure 4, sorafenib was unable to influence the subcellular distribution of AR as well as its c-terminally truncated $\mathrm{AR} \triangle \mathrm{LBD}$-counterpart $\mathrm{AR}^{\mathrm{Q} 640 \mathrm{X}}$.

Figure 4. Sorafenib does not modulate subcellular distribution of $A R$ and $A R \triangle L B D$ in PCa cells. PC-3 cells were transfected with either pAR-t1EosFP or pEGFP-ARQ640X coding for green fluorescent AR-EosFP and ARQ640X-EGFP fusion proteins [17,21]. Cells were treated with sorafenib $5 \mu \mathrm{M}$ (SORA) in the absence/presence of DHT (10 nM). Intracellular localization of AR-EosFP and AR $\triangle$ LBD-EGFP was determined by fluorescence microscopy. (A) Effect of sorafenib on the subcellular distribution of the AR. Left panel: Fluorescence microscopy of AR-EosFP transfected cells. Right panel: Percentage of cells expressing cytoplasmic (black bars) or nuclear fluorescence (white bars), (a) untreated controls; (b) sorafenib; (c) Dihydrotestosterone (DHT); (d) sorafenib + DHT; (B) Effect of sorafenib on the subcellular distribution of the ARLBD. Left panel: Fluorescence microscopy of AR $\triangle$ LBD-EGFP transfected cells. Right panel: Percentage of cells expressing cytoplasmic (black bars) or nuclear fluorescence (white bars); (e) untreated controls; (f) sorafenib.

A
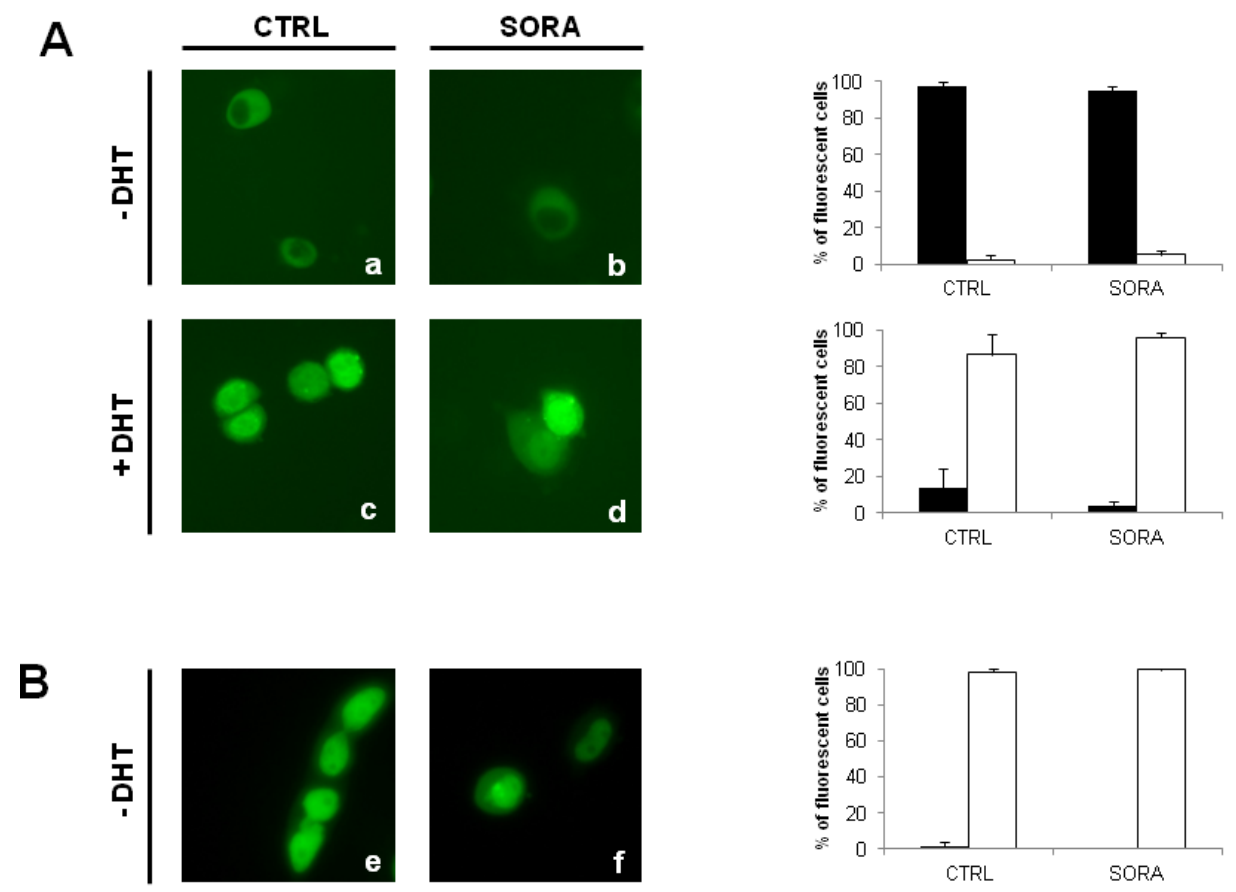

\subsection{Inhibition of Cell Proliferation after Sorafenib-Treatment in PCa Cell Lines}

Based on the observation that sorafenib is able to inhibit AR as well as ARALBD-signalling we further investigated the antiproliferative effects of the compound on the androgen sensitive LNCaP 
$(\mathrm{AR}+)$ cells, the castration resistant 22Rv1 ( $\mathrm{AR}+, \mathrm{AR}-\mathrm{V}+)$ cells as well as the androgen insensitive PC-3 (AR-) and DU-145 (AR-) cells using a MTT cell viability assay [27]. As depicted in Figure 5, the antiproliferative effects of sorafenib were more pronounced in AR-positive or AR/AR-V-positive prostate cancer cells as compared to those lacking the androgen receptor. Differences between $\mathrm{AR}+$ and AR- cells were statistically significant at a sorafenib concentration of $2.5 \mu \mathrm{M}$ (proliferation rate $\mathrm{LNCaP}: 60 \% \pm 5 \%$ and $22 \mathrm{Rv} 1: 76 \% \pm 3 \%$ versus $\mathrm{PC}-3: 82 \% \pm 3 \%, p=0.002$ and $p=0.036$, respectively).

Figure 5. Effect of Sorafenib on prostate cancer cell proliferation. PCa cell lines PC-3 (AR-), DU-145 (AR-), LNCaP (AR+) and 22Rv1 (AR+/AR-V+) were seeded in 96-well plates and allowed to adhere overnight. Subsequently, medium was changed, and cells were grown in RPMI-1640, supplemented with 5\% fetal bovine serum and antibiotics in the presence/absence of sorafenib. Cell proliferation was assessed by means of a colorimetric MTT-Assay. (A) Dose response curve of sorafenib-induced growth inhibition. PCa cells treated for $72 \mathrm{~h}$ with increasing concentrations of sorafenib $(0-5 \mu \mathrm{M})$. Growth inhibition is expressed as percent of untreated controls, which were set at $100 \%$ (* $p<0.05$; ** $p<0.01, * * * p<0.001$ ); (B) Time course of sorafenib-induced antiproliferative effects in PCa cells. PCa cells treated with sorafenib $(5 \mu \mathrm{M})$ for different periods of time. Results are expressed as percent of untreated controls, which were set at $100 \%$.

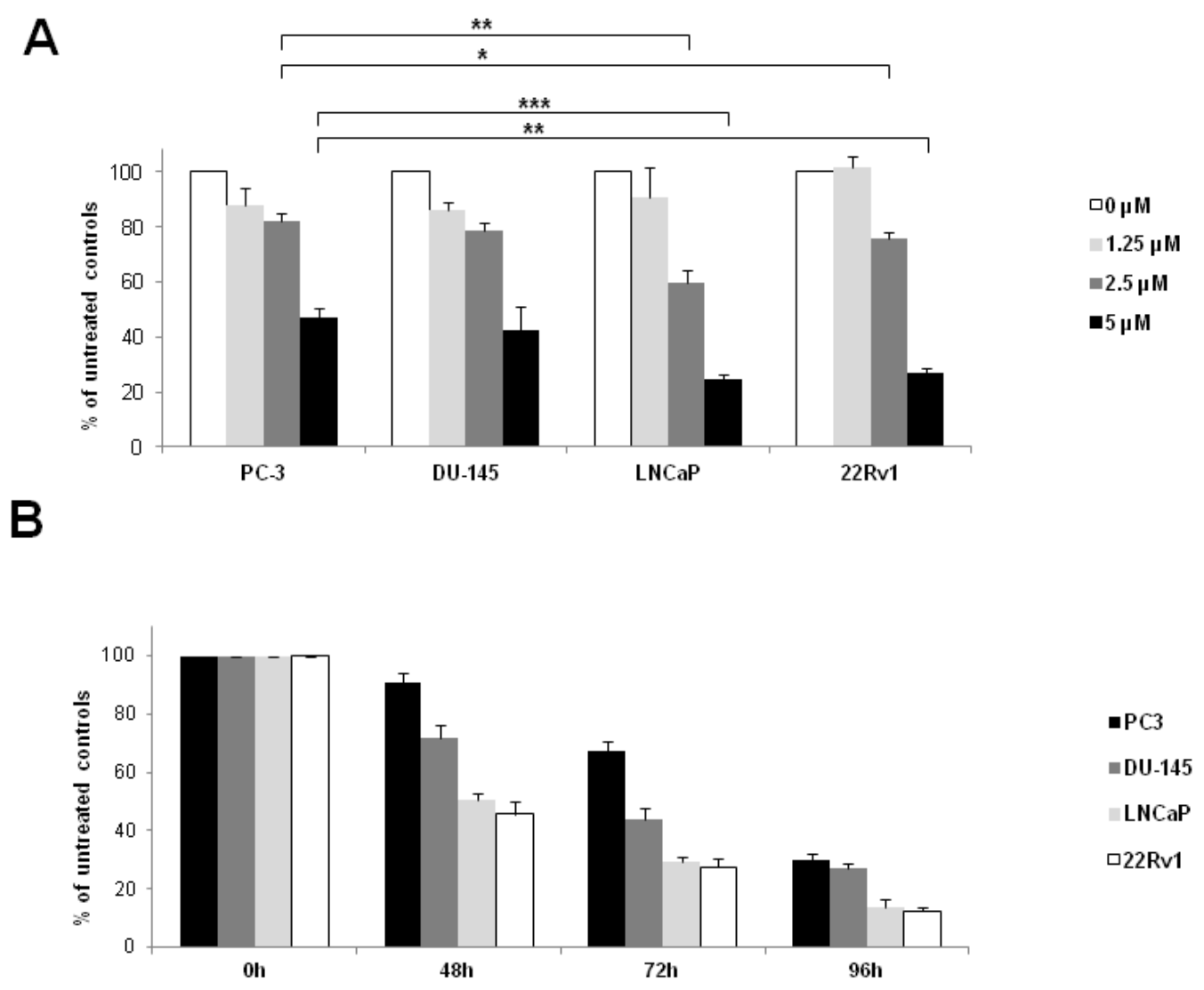




\section{Experimental Section}

\subsection{Plasmids and Chemicals}

pSG5-AR encoding a wild-type full-length AR (919 amino acids) was supplied by Dr. H. Klocker (Innsbruck, Austria). pAR-t1EosFP coding for a green fluorescent Eos-AR-fusion protein was a generous gift from Dr. F. Oswald (Ulm, Germany). pCruz-ARQ640X and pEGFP-ARQ640X coding for the $C$-terminally truncated ARQ640X (aa 1-640) were provided by and Dr. J. Céraline (Strasbourg, France). The PSA reporter plasmid pPSA-61luc under control of a $6 \mathrm{~kb}$-fragment of the human PSA-promoter was a generous gift of Dr. J. Trapmann (Rotterdam, The Netherlands). The artificial $\operatorname{ARE}(2 x)$ reporter plasmid pLC0548 (pARE(2x)-luc) under control of a synthetic ARE-promoter was created by H. Lebedur and provided by Dr. A. Allera (Bonn, Germany). Renilla reniformis luciferase reporter plasmid (pRL-TK) was purchased from Promega (Mannheim, Germany). Dihydrotestosterone (DHT) and the proteasome inhibitor MG132 were purchased from Sigma-Aldrich GmbH (Taufkirchen, Germany). Sorafenib was a product of LKT Laboratories Inc. (St. Paul, MN, USA). All other chemicals, if not specified, were products of Sigma-Aldrich GmbH (Taufkirchen, Germany).

\subsection{Cell Culture}

PC-3, DU-145, 22Rv1 and LNCaP cells were purchased from the American Type Culture Collection (Manassas, VA, USA). Cell culture was performed as recently described [21].

\subsection{Reporter Gene Assays}

PC-3 cells were transiently cotransfected in 24-well plates with AR-expression plasmids (pSG5-AR; pCruz-Q640X) and different reporter gene constructs (pPSA-61luc, pARE(2x)-luc) using the transfection reagent Polyfect (Qiagen, Hilden, Germany). pRL-TK was cotransfected as an internal control for transfection efficiency. Subsequently, cells were treated with/without $1 \mathrm{nM} \mathrm{DHT.} \mathrm{After}$ $24 \mathrm{~h}$, reporter gene activity was measured using the Dual-Luciferase Reporter Assay (Promega GmbH, Mannheim, Germany). In this experimental set-up, the PSA- and ARE-reporters are correlated with the effects of the specific experimental conditions, while the activity of the co-transfected constitutive pRL-TK reporter provides an internal control that serves as the baseline response. Normalizing the activity of the experimental PSA- and ARE-reporters to the activity of the internal control minimizes experimental variability caused by differences in cell viability, transfection efficiency, general effects on transcription, translation or protein stability. All experiments were performed as recently described [17].

\subsection{Nuclear Translocation Assay}

PC-3-cells were seeded in 24-well plates and grown in the absence of DHT for $24 \mathrm{~h}$. Subsequently, cells were transfected with pAR-t1EosFP and pEGFP-ARQ640X. After $24 \mathrm{~h}$, cells were treated with ethanol (solvent control), $10 \mathrm{nM}$ DHT, ethanol $+5 \mu \mathrm{M}$ Sorafenib or $10 \mathrm{nM}$ DHT $+5 \mu \mathrm{M}$ Sorafenib for $2 \mathrm{~h}$. The fluorescent cells were subsequently counted using a fluorescent microscope as recently described [17,28]. 


\subsection{Proliferation Assay}

Cell viability was determined by means of a colorimetric MTT assay. This assay is based on the the reduction of tetrazolium salts to formazan derivatives by functional mitochondria. The assay was performed as described by Mosmann [27].

\subsection{Western Blot Analysis and Immunodetection of AR and AR $\triangle L B D$}

Total proteins were extracted from cells using RIPA buffer. $40 \mu \mathrm{g}$ of lysate were separated by Sodium dodecyl sulfate polyacrylamide gel electrophoresis (SDS-Page). Subsequently proteins were transferred onto a PVDF membrane (Invitrolon ${ }^{\mathrm{TM}}$ PVDF, Invitrogen, Carlsbad, CA, USA) by semi-dry blotting. AR and AR $\triangle$ LBD were detected using the monoclonal antibody AR441 (Dako Deutschland $\mathrm{GmbH}$, Hamburg, Germany) at a dilution of 1:2.000 in Tris buffered saline, 0.1\% Tween20 (v/v) (TBS-T). Beta-actin served as a loading control using a mouse monoclonal antibody directed against beta-actin (ab8224, Abcam, Cambridge, UK). Immunoreactive bands were detected using a 1:20.000 dilution of peroxidase-coupled secondary goat anti-mouse IgG (sc-2031, SantaCruz Biotechnology Inc., Santa Cruz, CA, USA) in TBS-T. Signals were visualized by the ECL Plus Chemiluminescent Substrate from Pierce (Rockford, IL, USA).

\subsection{Statistical Analysis}

Data are reported as means \pm standard deviations. Statistical significance was determined by an analysis of variance (ANOVA). One-way ANOVA results were confirmed with Bonferroni's multiple comparison tests. All analyses were performed with the use of SPSS Statistics (version 19.0; SPSS Software, Chicago, IL, USA, 2010).

\section{Conclusions}

Only recently, the efficacy of various tyrosine kinase inhibitors has been evaluated in the treatment of advanced PCa [29-33]. So far, several clinical phase II trials analyzing the impact of a sorafenib-monotherapy on CRPCa reported only moderate therapeutic effects [34-37]. Unfortunately, interpretation of the clinical data generated from these studies is hampered by the relatively low number of patients enrolled in these trials and a limited knowledge about the molecular changes in CRPCa cells following sorafenib treatment.

In vitro studies analyzing the precise molecular effects of the multikinase inhibitor sorafenib on CRPCa cells are sparse [38,39]. Recently, Oh et al. showed that sorafenib affects AR-signalling in PCa cell lines grown in presence of the synthetic androgen R1881. Inhibition of the canonical AR-signalling pathway after sorafenib treatment was due to a downregulation of AR-levels by an unknown mechanism [15]. To our knowledge, the present study is the first to demonstrate that sorafenib is able to inhibit signalling of $C$-terminally truncated, constitutively active $\mathrm{AR}$ variants (AR $\triangle \mathrm{LBD}$ ), the latter are thought to be key players in the development of CRPCa. Interestingly, inhibition of AR- as well as AR $\triangle$ LBD-signalling was paralleled by a sorafenib-induced proteasomal degradation of both receptor types. Consistently, the antiproliferative effects of sorafenib in our experimental model were the most pronounced in AR- or AR/AR $\triangle \mathrm{LBD}$-positive PCa cells as 
compared to their AR-negative counterparts (proliferation rate: 22Rv1/LNCaP $<$ PC-3/DU-145). Our finding of a dose-dependent decrease in PCa cell growth after sorafenib treatment is in accordance with previous findings by $\mathrm{Oh}$ et al. [15]. However, in our study the sorafenib concentrations necessary to induce significant antiproliferative effects were higher than those described by Oh et al. At least partially, this may be due to the varying experimental settings used in both studies. Oh and colleagues determined the antiproliferative effect of sorafenib treatment by measuring ${ }^{3} \mathrm{H}$-thymidine incorporation after $48 \mathrm{~h}$ in PCa cells that were grown and treated in serum free HITES medium (containing hydrocortisone, insulin, transferrin, estrogen, and selenium). By contrast, in our experiments PCa cells were grown in RPMI-1640 under standard conditions (10\% fetal bovine serum, antibiotics), cell viability following sorafenib treatment was determined after $72 \mathrm{~h}$ using an MTT-assay which reflects mitochondrial activity by measuring the reduction of tetrazolium salts to formazan derivatives. Therefore it is conceivable that the concentration dependencies may differ in both studies.

In line with our observations, Beardsley et al. presented encouraging results using a combination therapy of sorafenib with the nonsteroidal anti-androgen bicalutamide in 39 chemotherapy naïve CRPCa patients. PSA declines or stable disease ( $\geq 6$ months) were observed in $47 \%$ of patients including $26 \%$ of patients previously progressing on bicalutamide monotherapy [40].

In summary, the present results suggest that a subset of advanced CRPCa patients, especially those who are expressing $\mathrm{AR}$ and/or $\mathrm{AR} \triangle \mathrm{LBD}$, might benefit from a sorafenib treatment. Moreover, strategies to combine multi-targeted kinase inhibitors like sorafenib with hormonal therapies warrant further experimental studies in CRPCa.

\section{Acknowledgments}

This work was supported by a Ferdinand Eisenberger Grant of the German Society of Urology, grant ID ZeF1/FE-11 (to Friedemann Zengerling), Action Lions Vaincre le Cancer, Luxembourg (to Marcus V. Cronauer) and the Schüchtermann Stiftung, Germany (to Michael Höpfner).

\section{Conflict of Interest}

The authors declare no conflict of interest.

\section{References}

1. Jemal, A.; Bray, F.; Center, M.M.; Ferlay, J.; Ward, E.; Forman, D. Global cancer statistics. $C A$ Cancer J. Clin. 2011, 61, 69-90.

2. Bluemn, E.G.; Nelson, P.S. The androgen/androgen receptor axis in prostate cancer. Curr. Opin. Oncol. 2012, 24, 251-257.

3. Feldman, B.J.; Feldman, D. The development of androgen-independent prostate cancer. Nat. Rev. Cancer 2001, 1, 34-45.

4. Locke, J.A.; Guns, E.S.; Lubik, A.A.; Adomat, H.H.; Hendy, S.C.; Wood, C.A.; Ettinger, S.L.; Gleave, M.E.; Nelson, C.C. Androgen levels increase by intratumoral de novo steroidogenesis during progression of castration-resistant prostate cancer. Cancer Res. 2008, 68, 6407-6415. 
5. Haile, S.; Sadar, M.D. Androgen receptor and its splice variants in prostate cancer. Cell Mol. Life Sci. 2011, 68, 3971-3981.

6. Ceraline, J.; Cruchant, M.D.; Erdmann, E.; Erbs, P.; Kurtz, J.E.; Duclos, B.; Jacqmin, D.; Chopin, D.; Bergerat, J.P. Constitutive activation of the androgen receptor by a point mutation in the hinge region: A new mechanism for androgen-independent growth in prostate cancer. Int. J. Cancer 2004, 108, 152-157.

7. Libertini, S.J.; Tepper, C.G.; Rodriguez, V.; Asmuth, D.M.; Kung, H.J.; Mudryj, M. Evidence for calpain-mediated androgen receptor cleavage as a mechanism for androgen independence. Cancer Res. 2007, 67, 9001-9005.

8. Hornberg, E.; Ylitalo, E.B.; Crnalic, S.; Antti, H.; Stattin, P.; Widmark, A.; Bergh, A.; Wikstrom, P. Expression of androgen receptor splice variants in prostate cancer bone metastases is associated with castration-resistance and short survival. PLoS One 2011, 6, e19059.

9. Zhang, X.; Morrissey, C.; Sun, S.; Ketchandji, M.; Nelson, P.S.; True, L.D.; Vakar-Lopez, F.; Vessella, R.L.; Plymate, S.R. Androgen receptor variants occur frequently in castration resistant prostate cancer metastases. PLoS One 2011, 6, e27970.

10. Harada, N.; Inoue, K.; Yamaji, R.; Nakano, Y.; Inui, H. Androgen deprivation causes truncation of the $C$-terminal region of androgen receptor in human prostate cancer LNCaP cells. Cancer Sci. 2012, 103, 1022-1027.

11. Chan, S.C.; Li, Y.; Dehm, S.M. Androgen receptor splice variants activate androgen receptor target genes and support aberrant prostate cancer cell growth independent of canonical androgen receptor nuclear localization signal. J. Biol. Chem. 2012, 287, 19736-19749.

12. Mostaghel, E.A.; Marck, B.T.; Plymate, S.R.; Vessella, R.L.; Balk, S.; Matsumoto, A.M.; Nelson, P.S.; Montgomery, R.B. Resistance to CYP17A1 inhibition with abiraterone in castration-resistant prostate cancer: Induction of steroidogenesis and androgen receptor splice variants. Clin. Cancer Res. 2011, 17, 5913-5925.

13. Gioeli, D.; Paschal, B.M. Post-translational modification of the androgen receptor. Mol. Cell Endocrinol. 2012, 352, 70-78.

14. Weigel, N.L.; Moore, N.L. Steroid receptor phosphorylation: A key modulator of multiple receptor functions. Mol. Endocrinol. 2007, 21, 2311-2319.

15. Oh, S.J.; Erb, H.H.; Hobisch, A.; Santer, F.R.; Culig, Z. Sorafenib decreases proliferation and induces apoptosis of prostate cancer cells by inhibition of the androgen receptor and Akt signaling pathways. Endocr. Relat. Cancer 2012, 19, 305-319.

16. Gaddipati, J.P.; McLeod, D.G.; Heidenberg, H.B.; Sesterhenn, I.A.; Finger, M.J.; Moul, J.W.; Srivastava, S. Frequent detection of codon 877 mutation in the androgen receptor gene in advanced prostate cancers. Cancer Res. 1994, 54, 2861-2864.

17. Streicher, W.; Zengerling, F.; Laschak, M.; Weidemann, W.; Hopfner, M.; Schrader, A.J.; Jentzmik, F.; Schrader, M.; Cronauer, M.V. AR-Q640X, a model to study the effects of constitutively active $C$-terminally truncated AR variants in prostate cancer cells. World J. Urol. 2012, 30, 333-339. 
18. Lapouge, G.; Erdmann, E.; Marcias, G.; Jagla, M.; Monge, A.; Kessler, P.; Serra, S.; Lang, H.; Jacqmin, D.; Bergerat, J.P.; et al. Unexpected paracrine action of prostate cancer cells harboring a new class of androgen receptor mutation-A new paradigm for cooperation among prostate tumor cells. Int. J. Cancer 2007, 121, 1238-1244.

19. Watson, P.A.; Chen, Y.F.; Balbas, M.D.; Wongvipat, J.; Socci, N.D.; Viale, A.; Kim, K.; Sawyers, C.L. Constitutively active androgen receptor splice variants expressed in castration-resistant prostate cancer require full-length androgen receptor. Proc. Natl. Acad. Sci. USA 2010, 107, 16759-16765.

20. Chen, S.; Xu, Y.; Yuan, X.; Bubley, G.J.; Balk, S.P. Androgen receptor phosphorylation and stabilization in prostate cancer by cyclin-dependent kinase 1. Proc. Natl. Acad. Sci. USA 2006, 103, 15969-15974.

21. Rinnab, L.; Schütz, S.V.; Diesch, J.; Schmid, E.; Kufer, R.; Hautmann, R.E.; Spindler, K.D.; Cronauer, M.V. Inhibition of glycogen synthase kinase-3 in androgen-responsive prostate cancer cell lines: Are GSK inhibitors therapeutically useful? Neoplasia 2008, 10, 624-634.

22. Agoulnik, I.U.; Bingman, W.E., III; Nakka, M.; Li, W.; Wang, Q.; Liu, X.S.; Brown, M.; Weigel, N.L. Target gene-specific regulation of androgen receptor activity by $\mathrm{p} 42 / \mathrm{p} 44$ mitogen-activated protein kinase. Mol. Endocrinol. 2008, 22, 2420-2432.

23. Hu, R.; Dunn, T.A.; Wei, S.; Isharwal, S.; Veltri, R.W.; Humphreys, E.; Han, M.; Partin, A.W.; Vessella, R.L.; Isaacs, W.B.; et al. Ligand-independent androgen receptor variants derived from splicing of cryptic exons signify hormone-refractory prostate cancer. Cancer Res. 2009, $69,16-22$.

24. Schütz, S.V.; Cronauer, M.V.; Rinnab, L. Inhibition of glycogen synthase kinase-3beta promotes nuclear export of the androgen receptor through a CRM1-dependent mechanism in prostate cancer cell lines. J. Cell Biochem. 2010, 109, 1192-1200.

25. Schütz, S.V.; Schrader, A.J.; Zengerling, F.; Genze, F.; Cronauer, M.V.; Schrader, M. Inhibition of glycogen synthase kinase-3 $\beta$ counteracts ligand-independent activity of the androgen receptor in castration resistant prostate cancer. PLoS One 2011, 6, e25341.

26. Jain, G.; Voogdt, C.; Tobias, A.; Spindler, K.D.; Moller, P.; Cronauer, M.V.; Marienfeld, R.B. IkappaB kinases modulate the activity of the androgen receptor in prostate carcinoma cell lines. Neoplasia 2012, 14, 178-189.

27. Mosmann, T. Rapid colorimetric assay for cellular growth and survival: Application to proliferation and cytotoxicity assays. J. Immunol. Methods 1983, 65, 55-63.

28. Cronauer, M.V.; Ince, Y.; Engers, R.; Rinnab, L.; Weidemann, W.; Suschek, C.V.; Burchardt, M.; Kleinert, H.; Wiedenmann, J.; Sies, H.; et al. Nitric oxide-mediated inhibition of androgen receptor activity: Possible implications for prostate cancer progression. Oncogene 2007, 26, $1875-1884$.

29. Sonpavde, G.; Periman, P.O.; Bernold, D.; Weckstein, D.; Fleming, M.T.; Galsky, M.D.; Berry, W.R.; Zhan, F.; Boehm, K.A.; Asmar, L.; et al. Sunitinib malate for metastatic castration-resistant prostate cancer following docetaxel-based chemotherapy. Ann. Oncol. 2009, $21,319-324$. 
30. Dror Michaelson, M.; Regan, M.M.; Oh, W.K.; Kaufman, D.S.; Olivier, K.; Michaelson, S.Z.; Spicer, B.; Gurski, C.; Kantoff, P.W.; Smith, M.R. Phase II study of sunitinib in men with advanced prostate cancer. Ann. Oncol. 2009, 20, 913-920.

31. Araujo, J.C.; Mathew, P.; Armstrong, A.J.; Braud, E.L.; Posadas, E.; Lonberg, M.; Gallick, G.E.; Trudel, G.C.; Paliwal, P.; Agrawal, S.; et al. Dasatinib combined with docetaxel for castration-resistant prostate cancer: Results from a phase 1-2 study. Cancer 2012, 118, 63-71.

32. Mathew, P.; Thall, P.F.; Bucana, C.D.; Oh, W.K.; Morris, M.J.; Jones, D.M.; Johnson, M.M.; Wen, S.; Pagliaro, L.C.; Tannir, N.M.; et al. Platelet-derived growth factor receptor inhibition and chemotherapy for castration-resistant prostate cancer with bone metastases. Clin. Cancer Res. 2007, 13, 5816-5824.

33. Dahut, W.L.; Scripture, C.; Posadas, E.; Jain, L.; Gulley, J.L.; Arlen, P.M.; Wright, J.J.; Yu, Y.; Cao, L.; Steinberg, S.M.; et al. A phase II clinical trial of sorafenib in androgen-independent prostate cancer. Clin. Cancer Res. 2008, 14, 209-214.

34. Steinbild, S.; Mross, K.; Frost, A.; Morant, R.; Gillessen, S.; Dittrich, C.; Strumberg, D.; Hochhaus, A.; Hanauske, A.R.; Edler, L.; et al.. A clinical phase II study with sorafenib in patients with progressive hormone-refractory prostate cancer: A study of the CESAR Central European Society for Anticancer Drug Research-EWIV. Br. J. Cancer 2007, 97, 1480-1485.

35. Chi, K.N.; Ellard, S.L.; Hotte, S.J.; Czaykowski, P.; Moore, M.; Ruether, J.D.; Schell, A.J.; Taylor, S.; Hansen, C.; Gauthier, I.; et al. A phase II study of sorafenib in patients with chemo-naive castration-resistant prostate cancer. Ann. Oncol. 2008, 19, 746-751.

36. Aragon-Ching, J.B.; Jain, L.; Gulley, J.L.; Arlen, P.M.; Wright, J.J.; Steinberg, S.M.; Draper, D.; Venitz, J.; Jones, E.; Chen, C.C.; et al. Final analysis of a phase II trial using sorafenib for metastatic castration-resistant prostate cancer. Br. J. Urol. Int. 2009, 103, 1636-1640.

37. Safarinejad, M.R. Safety and efficacy of sorafenib in patients with castrate resistant prostate cancer: A Phase II study. Urol. Oncol. 2008, 28, 21-27.

38. Huang, R.; Chen, X.Q.; Huang, Y.; Chen, N.; Zeng, H. The multikinase inhibitor sorafenib induces caspase-dependent apoptosis in PC-3 prostate cancer cells. Asian J. Androl. 2010, 12, $527-534$.

39. Ullen, A.; Farnebo, M.; Thyrell, L.; Mahmoudi, S.; Kharaziha, P.; Lennartsson, L.; Grander, D.; Panaretakis, T.; Nilsson, S. Sorafenib induces apoptosis and autophagy in prostate cancer cells in vitro. Int. J. Oncol. 2010, 37, 15-20.

40. Beardsley, E.K.; Hotte, S.J.; North, S.; Ellard, S.L.; Winquist, E.; Kollmannsberger, C.; Mukherjee, S.D.; Chi, K.N. A phase II study of sorafenib in combination with bicalutamide in patients with chemotherapy-naive castration resistant prostate cancer. Invest. New Drugs 2012, $30,1652-1659$.

(C) 2012 by the authors; licensee MDPI, Basel, Switzerland. This article is an open access article distributed under the terms and conditions of the Creative Commons Attribution license (http://creativecommons.org/licenses/by/3.0/). 